\title{
Comparison of Ketamine-Midazolam-Propofol
}

\section{Combination and Fentanyl-Midazolam-Propofol}

\section{Combination for Sedation in Colonoscopy}

\author{
Selda Kayaaltı ${ }^{{ }^{*}}$, Ömer Kayaalttı ${ }^{2}$ \\ ${ }^{1}$ Dept. of Anaesthesiology and Reanimation, Develi Hatice-Muammer KOCATÜRK Public Hospital, Kayseri, Turkey \\ ${ }^{2}$ Dept. of Computer Technology, Develi Hüseyin Şahin Vocational College, Kayseri University, Kayseri, Turkey
}

\begin{abstract}
In this study, we aimed to compare the combination of ketamine-midazolam-propofol (KMP group) with fentanylmidazolam-propofol (FMP group) for sedoanalgesia in ASA I-II adult patients undergoing colonoscopy in terms of patient satisfaction, side effects, and technical characteristics such as procedure duration and recovery time.

A total of 60 ASA I-II patients who underwent colonoscopy were randomly divided into two groups. Both groups received $1 \mathrm{mg}$ midazolam and 30-50 mg propofol. $50 \mathrm{mg}$ ketamine was administered to the KMP group and $50 \mathrm{mg}$ fentanyl to the FMP group. The additional dose of propofol was determined by the anesthesiologist to achieve 4-5 sedation level of Ramsay Sedation Scale. At the end of the procedure, propofol consumption dose, side effects, the duration of the procedure, and the recovery time of the patients were recorded. Mann-Whitney U test, Chi-square, and Fischer's exact test were used to analyze data.

Total propofol consumption of FMP group was significantly higher $(\mathrm{p}<0.05)$ than KMP group. The procedure time in the FMP group was significantly lower $(\mathrm{p}<0.05)$ than the KMP group.

The combination of ketamine-midazolam-propofol and fentanyl-midazolam-propofol can be used safely in terms of patient satisfaction and cardiovascular and other possible side effects. The combination of ketamine-midazolam-propofol is superior to the combination of fentanyl-midazolam-propofol thanks to the use of propofol in lower quantities.
\end{abstract}

Key Words: Colonoscopy, Sedation, Ketamine, Fentanyl, Propofol

\section{Introduction}

During the gastrointestinal endoscopy procedure for diagnosis or treatment, sedation is performed in many centers. During the esophagogastroduodenoscopy procedure, the feeling of tingling and suffocation is frequently encountered, and the patients feel uncomfortable because of the abdominal pain, swelling, and embarrassment (1). Colonoscopy sedation reduces the discomfort and anxiety of patients, it also provides an environment for the endoscopist to increase success and comfort during the procedure (2). Today, It is still a matter of debate as to which medicines are to be used for sedation especially during time-consuming procedures such as colonoscopy and endoscopic retrograde cholangiography, and which combination is less risky or cost-effective (3).

Alfentanil, fentanyl, and midazolam are the most commonly used sedoanalgesic agents. They provide rapid induction and rapid recovery with minimal residual effect $(4,5)$. Propofol is an agent that anesthesiologists often use either alone or in various combinations due to quick start and short duration of its effect $(6,7)$. However, in some interventional procedures, higher doses are needed for the patient to be able to tolerate the procedure. High doses can lead to life-threatening complications such as hypotension and respiratory depression (8). By adding adjuvant drugs to propofol in the sedation protocol, the total drug consumption and the possibility of side effects are reduced and the collection time is shortened (9).

The ketamine is an N-methyl-D aspartate (NMDA) receptor antagonist that provides dissociative anesthesia (10). Despite the presence of analgesic effect of ketamine, it is not one of the frequently used agents in endoscopic procedures in adults due to hallucinations and delirium $(11,12)$. However, there are studies (13-16) in which ketamine is used in adult day-care patients during various interventional procedures such as (dental, gynecological, and endoscopic). There is no analgesic effect of midazolam, but its use makes amnesia after the procedure (17). 
Table 1. Patients' demographic data

\begin{tabular}{|c|c|c|c|c|c|c|c|}
\hline & & FMP Group & & KMP Group & & & \\
\hline & & $\begin{array}{l}\text { Mean } \pm \text { SD } \\
\mathrm{n}(\%)\end{array}$ & Median & $\begin{array}{l}\text { Mean } \pm \text { SD } \\
\mathrm{n}(\%)\end{array}$ & Median & $\mathrm{p}$ & \\
\hline Age & & $53.2 \pm 14.9$ & 57.5 & $59.9 \pm 11.8$ & 62.0 & 0.094 & $\mathrm{~m}$ \\
\hline Sex & $\begin{array}{l}\text { Female } \\
\text { Male }\end{array}$ & $\begin{array}{l}16(53.3 \%) \\
14(46.7 \%)\end{array}$ & & $\begin{array}{l}17(56.7 \%) \\
13(43.3 \%)\end{array}$ & & 0.795 & $\mathrm{X}^{2}$ \\
\hline ASA & $\begin{array}{l}\text { I } \\
\text { II }\end{array}$ & $\begin{array}{l}16(53.3 \%) \\
14(46.7 \%)\end{array}$ & & $\begin{array}{l}11(36.7 \%) \\
19(63.3 \%)\end{array}$ & & 0.194 & $\mathrm{X}^{2}$ \\
\hline
\end{tabular}

m Mann-Whitney u test / $\mathrm{X}^{2}$ Chi-square test

In our study, we added midazolam to both sedation protocols (ketamine -propofol and fentanyl-propofol) to less reminiscence of the emotional stress that they experienced during and before the procedure, and hallucinations that may occur due to ketamine and to help patients feel less discomfort during the procedure. We aimed to compare two sedation protocols in terms of side effects and patient satisfaction by adding fentanyl or ketamine as the third agent to propofol and midazolam agents frequently used in patients who will undergo colonoscopy.

\section{Materials and Methods}

After approval of the ethics committee of Erciyes University Medical Faculty (Unique Protocol ID: 2018/94) and the informed consent of the patients, 60 patients in the American Society of Anesthesiologists (ASA) I-II group, aged 18-75 years, who underwent elective colonoscopy, were included in the study. The study protocol was registered at ClinicalTrials.gov (NCT03607110; https://clinicaltrials.gov/ct2/show/NCT0360711 $0)$. The demographic information of the patient admitted to study is given in Table 1. ASA III-IV$\mathrm{V}$ group patients with uncontrolled chronic disease (uncontrolled diabetes mellitus (DM) and hypertension), severe respiratory and cardiopulmonary insufficiency, or liver and renal failure, and not accepting the procedure were excluded from the study. Patients with long-term analgesic, opioid, sedative use history, hypersensitivity to study drugs, egg and soybean oil, pregnancy or pregnancy suspected or lactating, and antipsychotic or antidepressant drug use history were also excluded from the study. Which group of patients were involved was determined by the sedative use history colonoscopy nurse randomly before the procedure.

The patient was given a proper diet before the operation, and bowel cleansing was performed. After 8 hours of fasting, the peripheral vascular route was opened with a $20 \mathrm{G}$ cannula, and $8 \mathrm{~mL}$ $\mathrm{kg} / \mathrm{hr}$ cristalloid solution was started. Prior to sedation, all patients were monitored for heart rate $(\mathrm{HR})$, mean arterial pressure (MAP) and peripheral oxygen saturation (SpO2), respiratory rate (SS) measurements. All patients were given $5 \mathrm{lt} / \mathrm{min}$ oxygen with nasal cannula. During the first 5 minutes of the procedure, the monitored data was recorded once every minute and once every 5 minutes in the subsequent period, and cardiopulmonary side effects were recorded during the procedure.

Sedation protocol: Both groups were initially administered $1 \mathrm{mg}$ of midazolam and 30-50 $\mathrm{mg}$ of propofol $(30 \mathrm{mg}$ in patients over 65 years old and $50 \mathrm{mg}$ in patients under 65 years). $50 \mathrm{mg}$ of ketamine and $50 \mathrm{mg}$ of fentanyl were applied to the KMP group and the FMP group respectively. After induction, it was aimed to have 4-5 sedation level of Ramsay Sedation Scale (18). When sedation score was lower than 4 or a $20 \%$ increase in baseline values in physiological parameters such as heart rate and blood pressure. $10 \mathrm{mg}$ propofol for patients over 65 years of age and $20 \mathrm{mg}$ propofol for patients under 65 years of age were administered (approximately half of the induction doses). At the end of the procedure, the total drug doses given to the patients, the duration of the procedure (withdrawal and collection time), and the patients' eye opening/recovery times were recorded.

Patient satisfaction: Patients were monitored until the Aldrete Recovery Score (ARS) was $\geq 9$. Patients with $A R S \geq 9$ were transferred to another eligible unit. Patients were asked questions about the procedure to assess patient satisfaction. Visual analogue scale (VAS) score $(0-10 \mathrm{~cm})$ was used in post-procedural pain assessment. The scale is anchored by "no pain" (score of 0) and "worst imaginable pain (score of 10). The patients were questioned about side effects and whether they remembered the procedure. In addition, patient satisfaction was recorded with satisfaction score 
Table 2. Information of propofol consumption, durations (reaching the cecum, operation, and recovery), patient satisfaction, operation re-preference, and recall of the operation

\begin{tabular}{|c|c|c|c|c|c|c|c|}
\hline & \multicolumn{2}{|c|}{ FMP Group } & \multicolumn{2}{|c|}{ KMP Group } & \multirow{2}{*}{\multicolumn{2}{|c|}{$\mathrm{p}$}} \\
\hline & & $\begin{array}{c}\text { Mean } \pm \text { SD } \\
\mathrm{n}(\%)\end{array}$ & Median & $\begin{array}{c}\text { Mean } \pm \text { SD } \\
\mathrm{n}(\%)\end{array}$ & Median & & \\
\hline \multicolumn{2}{|c|}{ Propofol Consumption Dose } & $80.7 \pm 29.6$ & 85.0 & $59.7 \pm 17.5$ & 50.0 & 0.002 & $\mathrm{~m}$ \\
\hline \multicolumn{2}{|c|}{ Reaching the Cecum (min.) } & $7.3 \pm 5.2$ & 7.0 & $4.9 \pm 2.2$ & 4.0 & 0.010 & $\mathrm{~m}$ \\
\hline \multicolumn{2}{|c|}{ Total Operation (min.) } & $13.4 \pm 6.6$ & 13.0 & $9.5 \pm 3.6$ & 8.50 & 0.047 & $\mathrm{~m}$ \\
\hline \multicolumn{2}{|c|}{ Eye Opening / Recovery (min.) } & $1.7 \pm 1.0$ & 1.0 & $2.0 \pm 0.8$ & 2.0 & 0.305 & $\mathrm{~m}$ \\
\hline \multicolumn{2}{|c|}{ VAS } & $0.3 \pm 0.7$ & 0.0 & $0.5 \pm 0.9$ & 0.0 & 0.259 & $\mathrm{~m}$ \\
\hline \multirow{4}{*}{$\begin{array}{l}\text { Patient } \\
\text { Satisfaction }\end{array}$} & Very good & $12(40.0 \%)$ & & $12(40.0 \%)$ & & \multirow{4}{*}{0.202} & \\
\hline & Good & $17(56.7 \%)$ & & $13(43.3 \%)$ & & & $\mathrm{X}^{2}$ \\
\hline & Not bad & $1(0.0 \%)$ & & $5(16.7 \%)$ & & & $X^{2}$ \\
\hline & $\mathrm{Bad}$ & $0(3.3 \%)$ & & $0(0.0 \%)$ & & & \\
\hline \multicolumn{2}{|c|}{ Operation Re-preference? } & $30(100.0 \%)$ & & $28(93.3 \%)$ & & 0.492 & $\mathrm{X}^{2}$ \\
\hline Recall of the & No & $29(96.7 \%)$ & & $27(90.0 \%)$ & & \multirow{2}{*}{0.301} & $\mathrm{X}^{2}$ \\
\hline Operation & Yes & $1(3.3 \%)$ & & $3(10.0 \%)$ & & & $X^{2}$ \\
\hline
\end{tabular}

m Mann-Whitney u test / $\mathrm{X}^{2}$ Chi-square test

of 4 points-scale (1 very good, 2 good, 3 not bad, $4 \mathrm{bad})$. Two days after the procedure, the patients were asked whether they would re-prefer this method if they entered the colonoscopy again, and their answers were recorded.

Statistical Analysis: Mean, standard deviation (SD), median, minimum, maximum, frequency, and ratio values were used in the descriptive statistics of the data. The distribution of the variables was measured by the Kolmogorov Simirnov test. Mann-Whitney $U$ test was used in the analysis of quantitative independent data. Chisquare test was used to analyze qualitative independent data, and Fischer test was used when chi-square test conditions were not met. SPSS 22.0 program was used for all analyzes.

\section{Results}

There was no significant difference in age, gender distribution, ASA distribution $(\mathrm{p}>0.05)$ between FMP and KMP groups in terms of demographics. When the propofol dose applied to the patient during the procedure was taken into account, the mean $\pm \mathrm{SD}$ medication dose was $80.7 \pm 29.6 \mathrm{mg}$ in the FMP group and $59.7 \pm 17.5 \mathrm{mg}$ in the KMP group. As a result, the amount of drug used in the FMP group was significantly higher $(\mathrm{p}<0.05)$ when compared to KMP group (see Table 2).

The effects of the two sedation protocols on the procedure time and recovery time were also evaluated. The total procedure time and time to reach the cecum in the FMP group was found to be significantly higher $(\mathrm{p}<0.05)$ than KMP group. There was no significance between the two groups when comparing the recovery time. When compared to groups in terms of recall of the procedure, 3 patients in the KMP and only one patient in the KMP group reminded the operation. However, there was no statistically significant difference $(\mathrm{p}>0.05)$ in the recall of the operation between the groups (see Table 2).

There were no more than 4 VAS values in both groups. $70 \%$ (21 patients) of the patients in the KMP group and $83.3 \%$ (25 patients) of the patients in the FMP group reported that they did not feel any pain. There was no significant difference $(p>0.05)$ between VAS values in the groups (see Table 2).

No patient reported a "bad" response, when the patient satisfaction score recorded after the procedure was reviewed. One patient in the FMP group and 5 patients in the KMP group expressed their satisfactions as "not bad", rest of patients responded "very good" or "good". Also, when asked if they would re-prefer the same method in the case of colonoscopy for the second time, all patients in both groups except 2 patients in the KMP stated that they would re-prefer the same method. A significant difference $(\mathrm{p}>0.05)$ was not found between the two groups in terms of patient satisfaction and re-prefer the same method (see Table 2).

The incidence of cardiovascular and other side effects between KMP and FMP groups did not differ significantly $(p>0.05)$. The side effects that 
Table 3. Side effects experienced by patients during the procedure

\begin{tabular}{|c|c|c|c|c|c|}
\hline & & FMP Group & KMP Group & & \\
\hline & & $\mathrm{n}(\%)$ & $\mathrm{n}(\%)$ & $\mathrm{P}$ & \\
\hline$\stackrel{\pi}{\Xi}$ & Hypotension & $5(16.7 \%)$ & $2(6.7 \%)$ & 0.228 & $\mathrm{X}^{2}$ \\
\hline$\stackrel{ْ}{g} \stackrel{0}{g}$ & Bradycardia & $1(3.3 \%)$ & $0(0.0 \%)$ & 1.000 & $X^{2}$ \\
\hline$\stackrel{\vec{J}}{\bar{I}}=$ & Desaturation & $0(0.0 \%)$ & $1(3.3 \%)$ & 1.000 & $\mathrm{X}^{2}$ \\
\hline பั & Nausea and Vomiting & $1(3.3 \%)$ & $0(0.0 \%)$ & 1.000 & $\mathrm{X}^{2}$ \\
\hline 0 & Headache & $0(0.0 \%)$ & $2(6.7 \%)$ & 0.492 & $\mathrm{X}^{2}$ \\
\hline
\end{tabular}

m Mann-Whitney u test / $\mathrm{X}^{2}$ Chi-square test

occurred during the procedure did not exceed 1 minute, and quickly returned to normal without any intervention. Side effects experienced by patients are given in Table 3.

Pulse and SpO2 values in the FMP and KMP groups did not differ significantly $(\mathrm{p}>0.05)$ at baseline, $1^{\text {st }}$ minute, $2^{\text {nd }}$ minute, $3^{\text {rd }}$ minute, $4^{\text {th }}$ minute, $5^{\text {th }}$ minute, and $8^{\text {th }}$ minute and after. Values of systolic blood pressures in the KMP group was significantly higher than the FMP group at $1^{\text {st }}$ minute, $2^{\text {nd }}$ minute, $4^{\text {th }}$ minute, $5^{\text {th }}$ minute, and $8^{\text {th }}$ minute and after. Values Diastolic blood pressures in the KMP group was also significantly higher than the FMP group at $4^{\text {th }}$ minute, $5^{\text {th }}$ minute, and $8^{\text {th }}$ and after (see Table 4 ).

\section{Discussion}

In this study, two sedation protocols prepared by adding fentanyl or ketamine to the combination of midazolam-propofol applied on colonoscopy were compared with respect to patient satisfaction, side effects, and the technical characteristics such as the duration of the procedure and the total propofol consumption.

In many countries, most of the endoscopic procedures are performed under sedation (19). Rex et al. [20] showed that patients successfully completed the endoscopy as awake. However, the vast majority of patients in developed countries prefer and demand to sleep during the procedure. In addition, sedation selection during the endoscopic procedures is directed toward a more potent sedation in time $(21,22)$. Sedation techniques and sedative agents used during colonoscopy vary from country to country, even from clinic to clinic. Propofol is a sedative, hypnotic, and amnesic agent used in painful procedures for diagnosis and treatment, and its popularity is increasing day by day. Propofol has no analgesic effect when used alone, but there is a synergistic effect when it used with opioids and benzodiazepines, but the optimal combination for sedation is still controversial. The use of propofol during colonoscopy increases both the rate of patient acceptance of the procedure and the quality of the procedure by increasing the diagnostic success $(3,19)$. Hsieh et al. (23) found that the use of propofol and meperidine combination was better than using propofol alone in terms of patient toleration and recovery. In addition, when propofol is combined with low doses of opioids or benzodiazepines, it provides effective analgesia and amnesia at doses below the hypnotic dose, and it is safer in terms of side effects as the other drugs used in lower doses in combination. In a study by Chiung-Dan Hsu et al. (24), one group was administered propofol as the sole agent propofol while it was applied to the other group in combination with midazolam and fentanyl. As a result of their studies, the total amount of propofol used was found to be lower in the fentanyl/midazolam/propofol group, while the incidence of hypotension and the duration of recovery were found to be high in the only propofol group.

In our study, if propofol was used alone for sedation during colonoscopy, since there was no analgesic property of propofol, it was likely that patients would move due to pain, so it would be difficult for the endoscope to perform the operation. If we provided the patient with a deeper sedation by increasing the dose of propofol in order for the endoscopist to make the procedure more comfortable, the side effects would also increase, and there would be a prolongation in the recovery time $(25,26)$. One of the factors that reduce endoscopist satisfaction is the delayed recovery of the patient. If patients are recovered early, the endoscopist will be able to handle more patients at the same time. For all these reasons, instead of using propofol alone, we used it in combination with two different agents. These agents were midazolam which we benefited from amnesia and ketamine or fentanyl which has analgesic properties. It is difficult to predict the appropriate dose of sedative agent for each patient. Overdose can be a problem especially in elderly patients (27). For

East J Med Volume:24, Number:2, April-June/2019 
Table 4. Hemodynamic changes during the procedure

\begin{tabular}{|c|c|c|c|c|c|c|c|}
\hline & \multicolumn{2}{|c|}{ FMP Group } & \multicolumn{2}{|c|}{ KMP Group } & \multirow[b]{2}{*}{$\mathrm{p}$} & \\
\hline & & Mean \pm SD & Median & Mean \pm SD & Median & & \\
\hline \multirow{7}{*}{ 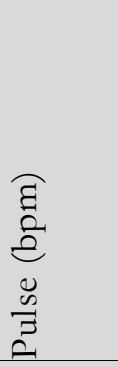 } & Baseline & $80.7 \pm 14.2$ & 81.5 & $84.2 \pm 11.7$ & 85.5 & 0.318 & $\mathrm{~m}$ \\
\hline & 1st min. & $77.8 \pm 11.0$ & 79.0 & $85.7 \pm 14.6$ & 84.0 & 0.057 & $\mathrm{~m}$ \\
\hline & 2nd min. & $75.0 \pm 10.4$ & 77.0 & $83.5 \pm 17.9$ & 81.0 & 0.083 & $\mathrm{~m}$ \\
\hline & 3rd min. & $76.0 \pm 10.9$ & 77.0 & $80.7 \pm 19.2$ & 79.5 & 0.679 & $\mathrm{~m}$ \\
\hline & 4th min. & $74.2 \pm 10.0$ & 75.0 & $80.1 \pm 18.5$ & 77.5 & 0.351 & $\mathrm{~m}$ \\
\hline & 5th min. & $73.4 \pm 11.2$ & 75.0 & $80.5 \pm 18.8$ & 78.0 & 0.249 & $\mathrm{~m}$ \\
\hline & $\geq 8$ th $\min$. & $73.5 \pm 11.0$ & 75.5 & $77.5 \pm 14.4$ & 75.0 & 0.521 & $\mathrm{~m}$ \\
\hline \multirow{7}{*}{ 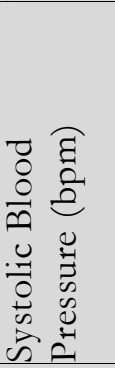 } & Baseline & $127.8 \pm 20.0$ & 128.0 & $136.1 \pm 22.3$ & 135.0 & 0.124 & $\mathrm{~m}$ \\
\hline & $1 \mathrm{st} \min$. & $117.3 \pm 19.6$ & 115.0 & $129.9 \pm 19.4$ & 132.5 & 0.025 & $\mathrm{~m}$ \\
\hline & 2nd min. & $109.1 \pm 17.8$ & 104.0 & $125.7 \pm 29.5$ & 121.5 & 0.012 & $\mathrm{~m}$ \\
\hline & 3rd min. & $114.6 \pm 20.3$ & 112.0 & $126.5 \pm 27.9$ & 123.0 & 0.063 & $\mathrm{~m}$ \\
\hline & 4th min. & $114.5 \pm 20.3$ & 110.0 & $131.8 \pm 30.3$ & 129.5 & 0.020 & $\mathrm{~m}$ \\
\hline & 5th min. & $117.6 \pm 22.1$ & 111.5 & $139.3 \pm 28.7$ & 141.0 & 0.002 & $\mathrm{~m}$ \\
\hline & $\geq 8$ th min. & $115.4 \pm 15.1$ & 112.0 & $142.3 \pm 26.7$ & 141.0 & 0.000 & $\mathrm{~m}$ \\
\hline \multirow{7}{*}{ 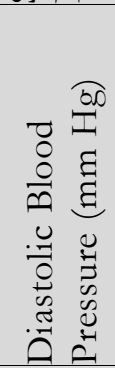 } & Baseline & $74.7 \pm 14.0$ & 76.0 & $73.4 \pm 13.4$ & 74.0 & 0.459 & $\mathrm{~m}$ \\
\hline & $1 \mathrm{st}$ min. & $68.0 \pm 16.1$ & 69.5 & $74.7 \pm 14.0$ & 74.0 & 0.196 & $\mathrm{~m}$ \\
\hline & 2nd min. & $64.2 \pm 15.2$ & 66.0 & $72.9 \pm 18.3$ & 69.0 & 0.092 & $\mathrm{~m}$ \\
\hline & 3rd min. & $67.7 \pm 12.1$ & 70.0 & $76.3 \pm 18.2$ & 75.5 & 0.063 & $\mathrm{~m}$ \\
\hline & 4th min. & $68.2 \pm 12.0$ & 69.0 & $78.7 \pm 17.9$ & 80.5 & 0.016 & $\mathrm{~m}$ \\
\hline & 5th min. & $71.6 \pm 11.9$ & 71.0 & $81.9 \pm 17.2$ & 82.0 & 0.014 & $\mathrm{~m}$ \\
\hline & $\geq 8$ th $\min$ & $70.2 \pm 11.0$ & 71.0 & $83.4 \pm 16.8$ & 82.0 & 0.001 & $\mathrm{~m}$ \\
\hline \multirow{7}{*}{$\begin{array}{l}\text { On} \\
\text { की }\end{array}$} & Baseline & $95.9 \pm 2.1$ & 96.0 & $94.4 \pm 2.7$ & 94.0 & 0.052 & $\mathrm{~m}$ \\
\hline & $1 \mathrm{st} \min$. & $95.1 \pm 2.2$ & 95.0 & $94.7 \pm 2.4$ & 95.0 & 0.671 & $\mathrm{~m}$ \\
\hline & 2nd min. & $95.9 \pm 2.2$ & 96.0 & $95.3 \pm 2.2$ & 95.5 & 0.414 & $\mathrm{~m}$ \\
\hline & 3rd min. & $96.2 \pm 2.3$ & 97.0 & $95.9 \pm 2.0$ & 95.5 & 0.490 & $\mathrm{~m}$ \\
\hline & 4th min. & $96.2 \pm 2.0$ & 97.0 & $96.3 \pm 1.9$ & 96.0 & 0.963 & $\mathrm{~m}$ \\
\hline & 5th min. & $96.6 \pm 1.7$ & 97.0 & $96.1 \pm 1.7$ & 96.0 & 0.184 & $\mathrm{~m}$ \\
\hline & $\geq 8$ th $\min$ & $92.5 \pm 17.2$ & 96.0 & $96.0 \pm 1.4$ & 96.0 & 0.839 & $\mathrm{~m}$ \\
\hline
\end{tabular}

m Mann-Whitney u test / $\mathrm{X}^{2}$ Chi-square test

this reason, we set the initial dose of propofol to 50 $\mathrm{mg}$ between 18-65 years and $30 \mathrm{mg}$ for patients over 65 years of age in our study.

In our study, the duration of procedure and time to reach the cecum was significantly higher $(\mathrm{p}<0.05)$ in the FMP group than in the KMP group. There was no significance between the two groups when comparing the recovery time. There are studies comparing recovery time between ketamine and fentanyl in the literature. The results of the studies were different. In two studies conducted by Akin et al. (15) and Chandar et al. (28), fentanyl-propofol and ketamine-propofol combinations were compared, and groups were found to be similar in terms of recovery times. In a study in pediatric patients (29), they found that the duration of recovery after fentanyl-propofol sedation was significantly longer compared with ketamine-propofol sedation. In a study conducted by Singh et al (30) in patients undergoing endoscopic ultrasonography, ketamine was found to cause lengthening of the recovery time when compared with fentanyl. Nalini KB et al. (31) used a combination of propofol-ketamine and propofol-fentanyl during a surgical intervention, unlike other studies. As a result of their study, they found that the propofol-ketamine combination was superior to the propofol-fentanyl group in terms of hemodynamic stability, respiratory side effects, postoperative analgesia, and recovery. They noted that both groups were evenly sedated at the end of operation and the first hour after, but the ARS at the 2nd hour after 
operation was significantly lower in the propofol ketamine group. Because the sedative effects of propofol may be antagonized by the arousal effects of ketamine, they thought that this result was emerging (31). Ketamine in sedative doses is associated with EEG activation, and increases awakeness (32).

We thought that the reason for these diversities may be the differences in the duration of the total procedure, the level of pain experienced during the procedure, the dosage of the medication used, the occurrence of the pediatric, or adult patients in the study patients.

The purpose of the combination of drugs is to achieve the desired effect using lower doses of drug for each agent. This leads to a reduction in the occurrence of side effects. Two studies $(33,34)$ showed that midazolam and fentanyl reduced the total propofol requirement for sedation during endoscopy. In our study, we added fentanyl or ketamine to the combination of propofolmidazolam. As a result of our study, we found that the total dose of propofol used in the FMP group was significantly higher than KMP group $(p<0.05)$. Similar to our results, Nalini KB et al. (31) found that the total amount consumption of propofol was significantly higher in the ketaminereceiving group compared to the fentanylreceiving group. There are also studies where different results are obtained. In two studies (15, 28) comparing fentanyl-propofol with ketaminepropofol, there was no significant difference between the groups in terms of the total propofol consumption. In the study that Tosun et al. (29) conducted in pediatric patients, a group was admitted with fentanyl-propofol and the other with ketamine-propofol. There was no significant difference between the two groups in total propofol consumption. However, $50 \%$ of patients in the fentanyl group needed additional propofol dose, whereas $17 \%$ of patients in the ketamine group needed additional propofol dose. In addition, $30 \%$ of the patients in the ketamine group did not need additional doses during the procedure, while this ratio was $7 \%$ in the fentanyl group. In a study of patients undergoing endoscopic ultrasonography (EUS) by Singh et al. (30), it was found that a single dose of fentanyl or ketamine reduced the total dose of propofol needed during EUS, but there was no significant difference between the two groups in terms of the total propofol dose used.

One of the most important reasons for sedation during colonoscopy is to make it easier for the patient to accept, and tolerate the procedure.
Therefore, the most important parameter in comparing the two groups in terms of patient satisfaction is whether or not they re-prefer the same method. Of course, the fact that the patient does not feel pain may cause him to re-prefer the same procedure, but this alone is not enough. Salman et al. (35) conducted a study on the satisfaction of the patients during colonoscopy and as a result of their study, they found 3 factors that affect patient satisfaction. These were physical discomfort, emotional stress, and total satisfaction. So pain is not a factor alone. Patients who feel uncomfortable due to a large number of health personnel in the room, and those who are ashamed, will prefer to sleep during the procedure even if they do not feel pain. For that reason, both our patients were evaluated with VAS, and patients were questioned in terms of patient satisfaction and re-preference of the procedure. Patient satisfaction was recorded by asking patients immediately after the procedure. Since the patient was affected by sedation, patients were asked whether they re-preferred the same method by telephone 2 days after surgery operation in order to avoid the effect of sedation. There was no difference between the two groups in terms of VAS score, patient satisfaction score, and patient re-preference of the procedure.

The NMDA receptor antagonist ketamine can reduce postoperative pain with central sensitization in the spinal dorsal horn trigeminal nucleus caudalis (10). Two studies $(31,36)$ showed that fewer patient in propofol-ketamine group required analgesics in rescue doses than propofol fentanyl group.

There was no serious side effect in both groups in our study. During our study, side effects such as bradycardia, hypotension, and desaturation occurred in some patients. However, these returned to normal within about 1 minute without medication intervention. Several studies showed that propofol-opioid combinations reduced ventilation and perfusion depending on the dose, lead to hypotension and bradycardia due to hemodynamic depression $(16,37,38)$. Guit et al. (39) also reported that the combination of fentanyl propofol resulted in hemodynamic depression, while the ketamine propofol combination provided stable hemodynamics. For this reason, FMP group was thought to have more hemodynamic and respiratory depression before the study begun, but we did not find any statistically significant difference between the two groups in terms of bradycardia and desaturation.

Side effects such as nausea, apathy, delirium, nystagmus, and severe muscle spasm can be seen 
after the application of ketamine or during the recovery (40). However, none of these side effects occurred in our patients. In a study by Guit et al. (39), it has been shown that the combination of propofol and ketamine eliminates these side effects. In our study, our results were similar to study results of Guit et al. (39). We thought that, In our study, ketamine-related agitation was not observed during recovery, because midazolam was used, As stated in the guideline written by Green et al. (41).

As a result, both KMP and FMP combinations provide effective and safe sedation in adult ASA III patients undergoing colonoscopy. Since the propofol consumption is low, the combination of KMP may be preferred. The limitation of our study is the small sample size of ASA I-II patients included in the study. There is a need for further studies with more patients.

Acknowledgement: We would like to sincerely thank general surgery specialists, Dr. Abdullah Haluk Şirin and Dr. Muhammed Emin Yenen, for their cooperation.

\section{References}

1. Ghanouni A, Plumb A, Hewitson P, Nickerson C, Rees CJ, von Wagner C. Patients' experience of colonoscopy in the English Bowel Cancer Screening Programme. Endoscopy 2016; 48: 232 240.

2. Ferreira AO, Cravo M. Sedation in gastrointestinal endoscopy: Where are we at in 2014? World J Gastrointest Endosc 2015; 7: 102 109.

3. Triantafillidis JK, Merikas E, Nikolakis D, Papalois AE. Sedation in gastrointestinal endoscopy: current issues. World J Gastroenterol 2013; 19: 463-481.

4. Sporea I, Popescu A, Sandesc D, Salha C, Sirli R, Danila M. Sedation during colonoscopy. Rom J Gastroenterol 2005; 14: 195-198.

5. Kilpatrick GJ, McIntyre MS, Cox RF, et al. CNS 7056A Novel Ultra-short-acting Benzodiazepine. Anesthesiology 2007; 107: 60-66.

6. Faulx AL, Vela S, Das A, et al. The changing landscape of practice patterns regarding unsedated endoscopy and propofol use: a national Web survey. Gastrointest Endosc 2005; 62: 9-15.

7. Singh H, Poluha W, Cheung M, Choptain N, Baron K, Taback S. Propofol for sedation during colonoscopy. Cochrane Database Syst Rev 2008; 8(CD006268).

8. Türk HŞ, Aydoğmuş M, Ünsal O, Köksal HM, Açik ME, Oba S. Sedation-analgesia in elective colonoscopy: propofol-fentanyl versus propofolalfentanil. Braz J Anesthesiol 2013; 63: 353-358.

9. Joo HS, Perks WJ, Kataoka MT, Errett L, Pace K, Honey RJ. A comparison of patient-controlled sedation using either remifentanil or remifentanilpropofol for shock wave lithotripsy. Anesth Analg 2001; 93: 1227-1232.

10. Bell R, Dahl J, Moore R, Kalso E. Peri-operative ketamine for acute post-operative pain: a quantitative and qualitative systematic review (Cochrane review). Acta Anaesthesiol Scand 2005; 49: 1405-1428.

11. Cohen LB, DeLegge MH, Aisenberg J, et al. AGA Institute review of endoscopic sedation. Gastroenterology 2007; 133: 675-701.

12. Regula J, Sokol-Kobielska E. Sedation in endoscopy: when and how. Best Pract Res Clin Gastroenterol 2008; 22: 945-957.

13. Sahin L, Sahin M, Aktas O, Kilic E, Mandollu E. Comparison of propofol/ketamine versus propofol/alfentanil for dilatation and curettage. Clin Exp Obstet Gynecol 2012; 39: 72-75.

14. Kramer KJ, Ganzberg S, Prior S, Rashid RG. Comparison of propofol-remifentanil versus propofol-ketamine deep sedation for third molar surgery. Anesth Prog 2012; 59: 107-117.

15. Akin A, Guler G, Esmaoglu A, Bedirli N, Boyaci A. A comparison of fentanyl-propofol with a ketamine-propofol combination for sedation during endometrial biopsy. J Clin Anesth 2005; 17: 187-190.

16. Heidari SM, Loghmani P. Assessment of the effects of ketamine-fentanyl combination versus propofol-remifentanil combination for sedation during endoscopic retrograde cholangiopancreatography. J Res Med Sci 2014; 19: 860-866.

17. Rai K, Hegde A, Goel K. Sedation in uncooperative children undergoing dental procedures: a comparative evaluation of midazolam, propofol and ketamine. J Clin Pediatr Dent 2007; 32: 1-4.

18. Ramsay M, Savege T, Simpson B, Goodwin R. Controlled sedation with alphaxalonealphadolone. British medical journal 1974; 2: 656.

19. Lin OS. Sedation for routine gastrointestinal endoscopic procedures: a review on efficacy, safety, efficiency, cost and satisfaction. Intest Res 2017; 15: 456-466.

20. Rex DK, Imperiale TF, Portish V. Patients willing to try colonoscopy without sedation: associated clinical factors and results of a randomized controlled trial. Gastrointest Endosc 1999; 49: 554-559.

21. Liu H, Waxman DA, Main R, Mattke S. Utilization of anesthesia services during outpatient endoscopies and colonoscopies and associated spending in 2003-2009. JAMA 2012; 307: 1178-1184. 
22. Predmore Z, Nie X, Main R, Mattke S, Liu H. Anesthesia service use during outpatient gastroenterology procedures continued to increase from 2010 to 2013 and potentially discretionary spending remained high. Am J Gastroenterol 2017; 112: 297-302.

23. Hsieh Y-H, Chou A-L, Lai Y-Y, et al. Propofol alone versus propofol in combination with meperidine for sedation during colonoscopy. J Clin Gastroenterol 2009; 43: 753-757.

24. Hsu C-D, Huang J-M, Chuang Y-P, et al. Propofol target-controlled infusion for sedated gastrointestinal endoscopy: A comparison of propofol alone versus propofol-fentanylmidazolam. Kaohsiung J Med Sci 2015; 31: 580584.

25. Church JM. Complete colonoscopy: how often? And if not, why not? Am J Gastroenterol 1994; 89: 556-560.

26. Quine M, Bell G, McCloy R, Charlton J, Devlin $\mathrm{H}$, Hopkins A. Prospective audit of upper gastrointestinal endoscopy in two regions of England: safety, staffing, and sedation methods. Gut 1995; 36: 462-467.

27. Bell G, Spickett G, Reeve P, Morden A, Logan R. Intravenous midazolam for upper gastrointestinal endoscopy: a study of 800 consecutive cases relating dose to age and sex of patient. Br J Clin Pharmacol 1987; 23: 241-243.

28. Chandar R, Jagadisan B, Vasudevan A. Propofolketamine and propofol-fentanyl combinations for nonanesthetist-administered sedation. J Pediatr Gastroenterol Nutr 2015; 60: 762-768.

29. Tosun Z, Aksu R, Guler G, et al. Propofol-ketamine vs propofol-fentanyl for sedation during pediatric upper gastrointestinal endoscopy. Paediatr Anaesth 2007; 17: 983-988.

30. Singh SA, Prakash K, Sharma S, Dhakate G, Bhatia V. Comparison of propofol alone and in combination with ketamine or fentanyl for sedation in endoscopic ultrasonography. Korean J Anesthesiol 2018; 71: 43-47.

31. Nalini K, Cherian A, Balachander H. Comparison of propofol and ketamine versus propofol and fentanyl for puerperal sterilization, a randomized clinical trial. J Clin Diagn Res 2014; 8: GC01GC04.

32. Frizelle HP, Duranteau J, Samii K. A comparison of propofol with a propofol-ketamine combination for sedation during spinal anesthesia. Anesth Analg 1997; 84: 1318-1322.

33. Elitsur Y, Blankenship P, Lawrence Z. Propofol sedation for endoscopic procedures in children. Endoscopy 2000; 32: 788-791.

34. Disma N, Astuto M, Rizzo G, et al. Propofol sedation with fentanyl or midazolam during oesophagogastroduodenoscopy in children. Eur J Anaesthesio 2005; 22: 848-852.

35. Salmon P, Shah R, Berg S, Williams C. Evaluating customer satisfaction with colonoscopy. Endoscopy 1994; 26: 342-346.

36. Mortero RF, Clark LD, Tolan MM, Metz RJ, Tsueda K, Sheppard RA. The effects of smalldose ketamine on propofol sedation: respiration, postoperative mood, perception, cognition, and pain. Anesth Analg 2001; 92: 1465-1469.

37. Abu-Shahwan I, Mack D. Propofol and remifentanil for deep sedation in children undergoing gastrointestinal endoscopy. Paediatr Anaesth 2007; 17: 460-463.

38. Tsui BC, Wagner A, Usher AG, Cave DA, Tang C. Combined propofol and remifentanil intravenous anesthesia for pediatric patients undergoing magnetic resonance imaging. Paediatr Anaesth 2005; 15: 397-401.

39. Guit J, Koning H, Coster M, Niemeijer R, Mackie D. Ketamine as analgesic for total intravenous anaesthesia with propofol. Anaesthesia 1991; 46: 24-27.

40. Shah A, Mosdossy G, McLeod S, Lehnhardt K, Peddle M, Rieder M. A blinded, randomized controlled trial to evaluate ketamine/propofol versus ketamine alone for procedural sedation in children. Ann Emerg Med 2011; 57: 425-433.

41. Green SM, Roback MG, Kennedy RM, Krauss B. Clinical practice guideline for emergency department ketamine dissociative sedation: 2011 update. Ann Emerg Med 2011; 57: 449-461. 